\title{
Surprise, Surprise - A Flying Squirrel! Learning to Protect the Unexpected
}

\author{
Nina V. Nygren ${ }^{\mathrm{a}, \#}$ and Taru Peltola ${ }^{\mathrm{b}}$ \\ ${ }^{a}$ Faculty of Management and Business, Tampere University, Tampere, Finland \\ ${ }^{\mathrm{b}}$ Finnish Environment Institute and University of Eastern Finland, Joensuu, Finland
}

\#Corresponding author. E-mail: nina.nygren@tuni.fi

\begin{abstract}
Non-human nature is often unpredictable and continues to surprise us. How can we take this into account and use it in ways leading to more robust conservation strategies? We analyse the emergence and implications of surprises in the context of conservation of strictly protected Siberian flying squirrels in Finland. Nocturnal, arboreal flying squirrels keep surprising surveyors, planners and landowners by their flickering presence. We use field interviews and other material to analyse surprises as relational and affective phenomena - both the surprised observer and an unexpected event are needed to create a surprise. We argue that surprises can help to reconsider situations and identify new knowledge about non-human nature, and hence improve conservation strategies.
\end{abstract}

Keywords: Siberian flying squirrel, surprise, conservation, affect, anticipation

\section{INTRODUCTION}

Unpredictability of nonhuman nature poses a challenge to nature conservation. Conservation of protected species relies on observations of these species. Yet, signs of presence are sometimes found in surprising places or the species appears to be unexpectedly absent. Such surprises might seem to suggest that conservation is based on vague knowledge or wrong premises. In this paper we explore possibilities to use surprises in ways that can lead to more robust conservation strategies. It is obvious that humans cannot ever fully understand the lives of other beings (Nagel 1974; Nygren and Jokinen 2013; Boonman-Berson et al. 2018). Nevertheless, we suggest that the unpredictability of nonhuman life could be turned into a resource rather than a constant problem in decision-making. This requires openness to the roots of surprises. Only by understanding how they stem from the unexpected can these

\begin{tabular}{|l|l|}
\hline \multicolumn{2}{|c|}{ Access this article online } \\
\hline Quick Response Code: & Website: \\
\hline & www.conservationandsociety.org \\
\cline { 2 - 3 } & \\
\hline
\end{tabular}

often-undesirable events facilitate learning processes and reflection on current conservation practices.

An unexpected event (e.g. Lindenmayer et al. 2010) is perhaps the first thing that comes into mind when thinking about surprise, but it can also be defined as a feeling, a physical reaction (e.g. Reisenzein et al. 2017). For the purposes of this paper we take a relational view to surprise - both the surprised observer and the unexpected event are needed to create a surprise. Such a view enables us to define the various sources of surprises and address the value and implications of surprises in developing conservation strategies.

Lindenmayer et al. (2010) have acknowledged the role of different types of 'ecological surprises' as catalysts for reformulating perceptions about the natural world, as well as outlined ways to anticipate ecological phenomena. In ecological research, the probability of surprises has been addressed to develop methods of reducing the amount of unwanted surprises and to improve the management of uncertainty. Attempts to manage uncertainty may, however, lead to what Ramírez and Ravetz (2011) have called 'feral futures'. Feral futures emerge when interventions in the unfolding of events by applying standard risk management procedures increase rather than decrease uncertainty. Ramírez and Ravetz introduce the notion metaphorically to designate the man-made risks of industrial societies, such as pandemics, global food risks or economic crises. They, however, situate the term with Darwin's work,

Copyright: (C) Nygren and Peltola 2020. This is an open access article distributed under the terms of the Creative Commons Attribution License, which permits unrestricted use and distribution of the article, provided the original work is cited. Published by Wolters Kluwer - Medknow, Mumbai | Managed and supported by the Ashoka Trust for Research in Ecology and the Environment (ATREE), Bangalore. For reprints contact: reprints@medknow.com 
'feral' referring to species once tame but returning to the wild, sometimes causing native species to disappear. 'Feral' is something that we, humans, have created and think we know. Feral futures are situations in which 'our previous experience can be misleading, and events that we thought we could predict or prevent turn out to be very different or could even have dire consequences' (Ramírez and Ravetz 2011: 479).

The notion of feral futures is helpful in detecting the root causes of surprises and responding to them. Surprises often emerge as a contrast to existing models and ways of thinking. Standardised practices and approaches considered normal create expectations about possible, plausible, or imaginable futures. While they may suggest that these visions of the future will remain dominant, they may rule out possible events that come as surprises just because they have been ignored. Surprises that challenge expectations can be deemed a problem in decision making requiring solid assessment of the situation. But to respond to the challenges they pose, surprising events could be understood in other terms, 'as an occurrence that triggers awareness of one's own ignorance' (Gross 2010: 5). The proposal to consider surprise as an asset in increasing awareness is in line with notions arising from psychology, where surprise has been modeled as an inherent part of sensemaking and learning (Maguire et al. 2011). Overall, the tension between the unknown and the known has been argued to form a crucial driver for the development of new knowledge, new perspectives and even new research designs (Rheinberger 1997; Lindermayer et al. 2010; Gross 2010; Davies 2013). Surprises make us aware of what is not known or considered when planning or making decisions, and therefore they should not be downplayed. Surprises should be regarded as a means of more 'careful' conservation (Hinchliffe 2008), questioning the adequacy of approaches taken and preparing us to learn more about the nature we aim to protect.

Gross (2010) points out that in some areas of landscape design and ecological restoration, the unpredictable and unknown characteristics of natural processes and events are accepted as a normal and sometimes even welcomed part of decision-making processes. However, some decision-making processes may be much less mindful and capable of dealing with nature that surprises or escapes attempts to govern it (Peltola and Heikkilä 2018). Especially when the processes are strictly regulated or outcomes risky it is more difficult to regard surprises as a normal condition and the tolerance towards them decreases. Such is the case in flying squirrel protection in Finland. We delve into the world of surprising elements in nature conservation by analysing the emergence and consequences of surprises in a context of nature survey and conservation practice of this species.

\section{FLYING SQUIRREL: HOW TO PROTECT AN ANIMAL WHOSE PRESENCE IS UNPREDICTABLE?}

Siberian flying squirrel (Pteromys volans) is a species present in the European Union in Finland and Estonia, and strictly protected by the EU Habitats Directive. In Finland, flying squirrels have affected both forest resource use and land use planning since the country's membership in the EU in 1995, and the incorporation of the species in the Habitats Directive Annex IV of strictly protected species (Haila et al. 2007; Nygren 2013).

Flying squirrels often surprise people who encounter them, whether they are surveyors mapping their presence or landowners, forest managers, politicians and urban planners making decisions concerning the forests they inhabit. These presences, absences and surprises have material, social, legal and economic consequences. Flying squirrels live in mixed, spruce-dominated forests in the southern part of Finland. The species is in decline, mainly because of intensified forest use in recent decades (Hanski 2006; Selonen et al. 2010; Liukko et al. 2016; Hyvärinen et al. 2019). After their insertion in the strictly protected species list of the EU in 1995, it has, however, been slowly discovered that they can be surprisingly abundant in the rather small, managed forest patches and forest edges near cities and villages (Santangeli et al. 2013; Mäkeläinen et al. 2015). As a protected species their presence means that the forest patch they are inhabiting should not be destroyed. Thus, flying squirrel surveys have become part of the normal nature survey practices in land use planning and forestry in Finland. These practices aim at minimising the risk of unexpected presence of the animal in areas under development or economic use.

The lifestyle and ecology of the Siberian flying squirrels make them good candidates for causing surprises to humans. The nocturnal and arboreal rodents themselves are almost never seen by surveyors themselves, who are usually surveying in daytime. Their presence is typically discovered by spotting faecal pellets at the bases of their preferred trees, mostly big aspens and spruce trees. The lack of direct observation makes it hard to understand precisely their habits and habitat use. Human judgement of the suitability of the habitat is often not the same as the animals' own. Flying squirrels were thought to prefer old-growth forests (e.g. Red book of Finland 1991), but they were later found to use even urban forests and forest edges (Mäkeläinen 2016). Similarly, many other species have been thought to avoid urban areas and their preference for urban habitats has been regarded as exceptional and unexpected (see Thomson 2007 regarding bats). In contrast, for modern day urban dwellers it may be surprising to know that many species that are nowadays common in cities, may have colonised urban areas relatively recently (see Vuorisalo et al. 2003 regarding crows). Signs of flying squirrel presence can be found in unexpected places and signs are often not found in places they have been found before because the local population is constantly moving and changing. New individuals are born, the young search for new territories, males move between the smaller home ranges of females, and individuals die. These changes and movements reflect the structure and features of the landscape providing suitable habitats for the squirrels, and they happen at a rate that is fast compared to the timescales of land use planning and forestry planning. Strict conservation of a 
relatively unpredictable animal is challenging and uncertainties might at worst risk the viability of the population.

While the ability to anticipate the presence of protected animals - for example, to identify a suitable habitat by surveying land areas - is a precondition for their conservation, the practices of anticipation are central to successful conservation measures. Facts about the presence of a protected species emerge through fieldwork practice, including the standardisation and disciplining of fieldwork. Yet, the facts often remain 'unfinished', meaning that the presence can be 'flickering' or derived from clues (Hinchliffe 2008; Nygren and Jokinen 2013; Boonman-Berson et al. 2018; Mahony et al. 2018). This forms our starting point: the practices of making flying squirrels present are also constitutive of surprises. The empirical case study in Finland allows us to explore how surprises are in fact co-created by human survey and conservation practices together with nonhuman creatures and their lifeworlds (Von Uexkull 2013; Ginn 2014), and how the surprises influence the practice of nature conservation. We demonstrate that the corporeality and affective nature of these practices direct policy implementation and influence the policy outcomes, that is, how well the 'flickering' presences of the squirrels can be taken into account in land and resource use planning.

In what follows, we first explain our theoretical perspective on surprises as relational affects arising from the practices of knowing and conserving the animals. We then introduce the materials and methods we have used in our analysis. We begin our analysis by explaining the ways surprises are framed through different affective experiences and impulses that redirect the practices of anticipation and then move on to the practices through which the presences of squirrels are anticipated, and on the other hand, how these practices produce surprises. In the discussion of our results we demonstrate the need to amend conservation practices. We link the experience of surprise with broader issues of conservation and suggest how capability of addressing unpredictability in conservation can be increased.

\section{SURPRISE AS AN AFFECTIVE IMPULSE}

We analyse surprises as bodily experiences formed in situated encounters between humans and animals, and in relation to the practices of conservation. We build on the assumption that possibilities for humans to create knowledge about other animals are formed in interactive processes with these animals. Mutual interactions between humans and nonhuman animals enable attuning to the differences, rhythms, and preferences of animals (Lorimer 2008; Brown and Dilley 2012; Jokinen and Nygren 2013; Mason and Hope 2014; Lorimer et al. 2017; O’Mahony et al. 2018; Boonman-Berson et al. 2018). This notion is derived from studies employing the concept of affect to study field surveys and knowing as embodied practices (Lorimer 2008; Jokinen and Nygren 2013; O'Mahony et al. 2018; Boonman-Berson et al. 2018). The concept of affect explains cognition in terms of changing bodily states, as 'a set of intensities' (Jones 2012). Affect theorists have pointed out that emotive processes direct human cognition and action (Nussbaum 2001; Milton 2002; Protevi, 2009), hence influencing how information about environment is interpreted and evaluated (Peltola et al. 2018).

Drawing on the philosophies of Spinoza and Deleuze, affects are understood as responsive capacities, which develop through interactions between humans and their surroundings (Anderson 2006; Adey 2008; Bennett 2010; Duff 2011). Rather than focusing on the affective experiences as such, studies on affect stress the relationality of bodily capacities: what a body is capable of doing — knowing, for example — depends on its various types of encounters with other bodies, understood in a broad sense (Adey 2008). Through their encounters with other bodies, including nonhumans, human bodies 'learn to be affected' by different elements in the world and articulate differences between them (Latour 2004; Hayes-Conroy 2010; Peltola and Tuomisaari 2015).

In studies of nature surveyors in action, the concept of affect has been used to explain how surveyors develop knowledge about wild animals by getting attuned to the animal ways of being (Lorimer 2008; Nygren and Jokinen 2013; O’Mahony et al. 2018; Boonman-Berson et al. 2018). In their study on flying squirrel surveyors, Nygren and Jokinen (2013) found out, for example, that the hope of finding an animal, a perceived feeling, appeared to increase the attunement of the surveyors to reading and recognising clues in the forest environment suggesting the animal's presence. This increased their chances of making observations. In turn, Peltola and Tuomisaari (2015) have analysed embodied knowing in the context of forestry decision making, and the capacities of forestry professionals to learn to be affected by various protected plant and animal species. O'Mahony et al. (2018) explain that fieldwork with wolves can be understood as 'translocated empathy' where the researcher emplaces themself on a map and attempts to 'think like a wolf' by using prior experiences, information from earlier research and cartographic interpretation. BoonmanBerson et al. (2018) illustrate that in order to count and manage wild boars, wildlife managers need 'to tune in on the wild boars and the wider ecology of the landscape'. Betz (2020) explains how community orchard volunteers attune to fruit trees to prune them.

All these studies emphasise that affects are not only corporeal but also relational and material: they arise out of the physical spaces we cohabit (Adey 2008; Thrift 2008), our routines and practices (Latour 2004; Hawkins 2010; Bennett 2010) or physical, virtual or technologically mediated encounters with other beings (Lorimer 2008; Brown and Dilley 2012; Nygren and Jokinen 2013; Mason and Hope 2014; O’Mahony et al. 2018; Boonman-Berson et al. 2018). Here we apply the concept to explain how surprises are formed in relation to the practices of anticipation and expectation, which aim to standardise the governance of flying squirrels, and their flickering presences. We further point out the role of embodied experiences in making the knowledge base for flying squirrel conservation more robust and sensitive to the 'unfinished' nature of the 
knowledge produced in human-nonhuman interactions and are constitutive of our attempts to conserve nature.

\section{MATERIALS AND METHODS}

\section{Research materials}

We analysed the fieldwork practices of two professional groups which are key to the implementation of flying squirrel conservation in Finland: professional flying squirrel surveyors and forestry professionals. The first of these groups, professional flying squirrel surveyors, collect data about the animals and map their whereabouts either as consultants, freelancers or public servants. This research material forms a timeline from the formation stage of flying squirrel surveying (2004-2006) to the mainstreaming of flying squirrel surveying among forestry professionals (2010-2011) (Nygren and Jokinen 2013; Peltola and Tuomisaari 2015). These survey practices have essentially remained the same because the conservation of the species is still done on a place-by-place basis (Wistbacka et al. 2018). The material collected about the work of flying squirrel surveyors consists of seven field interviews from Pirkanmaa region, Southern Finland. Three of the surveyors were also interviewed in their office before or after the field interview. One of the surveyors worked as a freelance surveyor, one worked for a consultancy, two were working for a municipality and one was the flying squirrel surveyor of the regional environmental authority. Most of the field interviews were connected with land use planning cases in the Tampere City Region, which is the second largest urban agglomeration in Finland.

The second group consists of public or private sector forestry professionals who are responsible for the operational planning of forestry. Trained as foresters or forest engineers they, in addition to their other tasks, help private forest owners, typically farmers or urban residents owning small forest holdings, meet legal requirements and forest certification standards for protecting biodiversity, or encourage them to enroll in a voluntary nature protection programme. Identifying and securing flying squirrel habitats forms a significant part of their responsibilities under the current legislation and conservation guidelines.

We use interviews with 19 forestry professionals working for both public and private organisations in Southern and Eastern Finland, conducted in 2010-2011. The thematic outline for interviews included questions about their personal histories, work routines, collaboration, and training. In addition to the interviews, fieldwork of these professionals was observed. Six of the informants were accompanied while completing tasks related to forestry extension and planning, timber procurement, logging-site planning, official inspections of logging sites, and environmental audits related to certification. The fieldwork situations included social interaction with colleagues, landowners, forest workers, and environmental authorities, and biodiversity-related field courses.

Similar to the field interviews with flying squirrel surveyors, accompanying the forestry professionals in the field enabled us to observe affective encounters and emotions shown, not only verbally expressed, by our informants (Brunet et al. 2019; Hayes-Conroy 2010). The fieldwork situations were specific in the sense that they induced emotional experiences that we could share with our informants. Unlike Betz (2020) or Hayes-Conroy (2010) studying community gardening and visceral experiences of slow food, we did not take part in the observed activities in the same manner as our informants. We sometimes searched at the bases of trees, peered for nesting holes and assessed the tree compositions with our informants and to some extent learned to be affected by forests and faeces, but the crucial difference is that our own professional success was not tied to producing reliable knowledge about flying squirrels. Therefore, we categorise ourselves more as observers than participants in the field encounters.

In addition, we have used diverse material on flying squirrel policy gathered since 2005 (Nygren 2013). The various documents, interviews and workshops with different stakeholders, ecological studies and reports, policy guides and legislation changes provide data on how particular survey and policy practices have stabilised and participate in the cocreation of surprises (Nygren 2013).

\section{Method: How to analyse surprising encounters}

We have analysed our field and interview materials by identifying surprising events encountered by the flying squirrel surveyors and professional foresters. We have identified these events both from the narratives that our informants have shared with us in interviews, and from our observations when we have followed these professionals while they have carried out fieldwork. The stories about surprising encounters with flying squirrels illustrate ways in which the fieldworkers perceive and experience the unexpected in their work, whereas our observations in specific and momentary research events (Hayes-Conroy 2010) allow us to explore how the unexpected is dealt with in everyday practices.

We further analyse the surprising events from the perspective of how surprises as a bodily experience are constituted. Rather than focusing on the elements of the experience as such we have identified linkages between the experience of surprise and the practices that have induced or condition the surprising event. This kind of analytical strategy enables to discuss the broader implications of the micro-level observations about the experience of surprise (Newman 2012), for example, to identify which broader rationalities the surprises are related to. Hence, we point out how surprises are framed in nature conservation: to which issues or practices they are related to and what conditions surprises.

Some affect theorists emphasise the unexpectedness of all our bodily experiences (e.g. Massumi 2002; Protevi 2009; Vanhanen 2010). For them, affects disrupt and are indeterminate, and there is always a 'slight surprise' in affective life (Anderson 2014). Yet, as Anderson (2014) reminds, experiences are not totally open-ended but mediated in many ways (see also Peltola and Tuomisaari 2015; Brunet et al. 
2019). It is this mediated character of surprises that we focus on in our analysis. Therefore, we use the material to expose what kind of expectations the affective practices of flying squirrel conservation generate and what kind of models for knowing the nonhuman and ways of thinking they stabilise. These explain why some events appear as surprising and unexpected.

\section{ANALYSIS}

The affective composition of surprise in professional conservation practice

\section{Perplexity}

"Yes I have thought about that, too, that how much is left unobserved, you can't possibly check every tree, if the area is large, you just can't [...] Once last year it happened that I went to that north side area and... I had been checking this area quite extensively already and... I was coming back here to the car and [...] I went to the field edge, it was a bigger spruce tree and there I noticed [faeces] for the first time, well what do you know. I had already concluded that there's nothing here because I had made a long round already and had found nothing and... coming back to the car I noticed there are flying squirrels here. I made a new round in the same area to take a better look and started finding them. [...]" (Biologist working for a municipal land-use planning department, field interview in April 2005)

Both flying squirrel surveyors and forestry professionals are normally perplexed when they find animals (or signs of animals) unexpectedly or do not find them when expected. One informant told a vivid story about a logger who found flying squirrel cubs on the hood of a harvester in the middle of a young pine forest. The logger could not anticipate the presence of the flying squirrel nest in this kind of habitat, so he phoned the informant astonished, nervous and afraid of having killed the animals. A surveyor of the regional environmental authority, in turn, found faeces underneath a dead nesting tree situated alone in a small clear-cut area during one of the observed field trips. In both cases the animal should have not been there: there were no large aspen or spruce trees nearby in the young pine forest which the harvester was logging, nor should a flying squirrel be able to survive in a single nesting tree $50 \mathrm{~m}$ away from the nearest suitable habitat in the middle of a clear-cut area.

The surveyors described their feelings when finding clues in a habitat they did not expect to find the flying squirrel. One surveyor told us it felt incredible that one quite small and isolated forest patch close to human habitation would host flying squirrels, as was revealed by observations brought to their attention, and later confirmed by themself. Another one told us about forestry professionals who had found faeces in a forest patch previously discarded as unsuitable.

In such cases, one needs to either accept their own misclassification of the habitat and accept the choice of the habitat of the flying squirrel or reject the findings as a clue or proof of a suitable habitat.

As Nygren and Jokinen (2013) write, the flying squirrel surveyors encounter different combinations of 'clues' in the forest. Some of these combinations incite more explanation, thinking and learning than others. Unexpected findings may add something new to their view. The surveyor either learns from the flying squirrel which kinds of habitats they may choose and starts pondering why exactly the flying squirrel has accepted this patch. Or the surveyor may reject the proof value of the faeces as signs of a suitable habitat, explaining the faeces presence as individuals getting lost or dispersing, or just passing thru by chance. It should be noted that either of these explanations for findings in a surprising place can be potentially 'true'. Learning the habitat suitability assessment is a long, individual learning process (Nygren and Jokinen 2013).

Nevertheless, surprising encounters with flying squirrels seem to be a resource for surveyors who wish to enhance their skills. Some surveyors explained that they explicitly try to find flying squirrels in different habitats, to avoid becoming too routinised. For the forestry professionals whose ability to find the animal served the purpose of fulfilling legal requirements for sustainable forestry, surprise does not offer such a luxury. Rather, it was always a sign of failure - a failure that may have legal consequences. For the forestry professionals it came as an unpleasant surprise that the clues they had followed when trying to ensure no flying squirrels were present in logging sites did not rule out the possibility of flying squirrel presence.

\section{Hope and disappointment}

In the case of professional flying squirrel surveyors, not finding signs of flying squirrels in what seemed like a suitable habitat is often connected to their passion for nature conservation. Several surveyors told us they were hoping to find flying squirrels in a "good" forest: mature, not overly managed forest with also other biodiversity values. They told us they were disappointed when flying squirrel signs were not found in such a forest because other findings didn't carry as much conservation obligations. Sometimes they judged the flying squirrels' choices for choosing forests too small, too isolated, too poor. Some felt that flying squirrel conservation guides the fate of the forests too much, sometimes leaving out 'good' forests and saving 'poor' forests.

Although forestry professionals often are relieved when no signs of the flying squirrel are found, making logging easier, the uncertainty about their presence can be hard to bear for them as well. One of them wanted to show us a special forest patch during the field trip. He told us he had managed to persuade the owner to voluntarily conserve the patch, and even to set aside a larger area he thought was valuable. His disappointment and frustration were visible when no faeces were found in the patch during the field visit. Since the flying squirrel is a mobile and 'flickering' species, absence of its faeces does not necessarily mean the absence of the animal or that they have abandoned the site. However, this uncertainty can be discouraging for the professionals who cannot be sure whether their painstaking efforts to take biodiversity values into account in their work have been successful. 


\section{Professional anxiety}

The surveyors are supposed to be professionals providing unambiguous and certain ecological knowledge (Nygren and Jokinen 2013). Although the surveyors are very well aware that unambiguous and certain knowledge is not obtainable, surprising presence/absence of the animals can raise professional anxiety among them. The surveyor working for the Regional Environment Centre who found the faeces in the middle of a logging site was clearly embarrassed by this surprise. At the time he was doing obligatory field checks on the basis of existing data. On a field trip he was accompanied by a forest professional who aspired to learn to identify flying squirrels but who was also in a position to represent the interests of the forestry owner. The faeces seemed to go counter to any knowledge on conservation and ecology of flying squirrels. Droppings in a wrong spot challenged prevailing ideas about the ecological requirements of the species underlying the efforts to protect it and regulate forestry practices. The droppings appeared to undermine the credibility of conservation knowledge — and of the flying squirrel expert in question.

While flying squirrel surveyors' identity and credibility as professionals can hinge on how they deal with uncertainty, the forestry professionals feel a different kind of anxiety. A destroyed flying squirrel habitat can lead to a police investigation, court and fines. This is why many interviewed forestry professionals described their attention to flying squirrel as acting for fear of punishment. Yet, failure to protect the animal does not necessarily lead to questioning of one's professional capacity among other forestry professionals or some landowners. In an interview one of them told about a colleague constantly joking about 'shooting a flying squirrel'. With such a tactical joke one may even try to maintain identity and credibility as a forestry professional among conservation skeptical landowners and colleagues (Peltola and Tuomisaari 2016).

However, anxiousness should not only be interpreted as a negative consequence of uncertainty. Anxious professionals may be more willing to let go of established ideas of expertise and authority and to look for knowledge that enables them to re-evaluate their own practice and the situation of the animal, a condition for taking 'feral' phenomena seriously (Ramírez and Ravetz 2011).

\section{Communicating surprises}

In addition to the surveyors and forestry professionals, flying squirrel findings often are a surprise for urban planners, forest owners, developers, inhabitants or forestr companies or other stakeholders. Findings may interrupt their expectations, hopes, fears and plans. Therefore, communicating the presence of the animal requires skills from the surveyors and forestry professionals who need to convince the stakeholders about solutions that enable them to live with flying squirrels. In these situations, the surveyors may feel they become the personifications of conservation, or, as one surveyor put it, personifications of restrictions to building. In the case of urban planning the surprise may have costly implications: the presence of a flying squirrel might influence expensive infrastructure projects such as road or railway construction or expected high-profit residential areas. In forestry, the landowners may get a compensation for the income losses arising from the protection of forest patches. Yet, flying squirrel findings often require the forestry professionals to negotiate with the landowners. This includes translating scientific arguments and legal requirements of conservation to a language that is understandable by people who do not find nature conservation their priority (see Peltola and Tuomisaari 2016). In some cases, the flying squirrel surveyors not only deliver the survey results but also continue working with the planners in order to find a solution to the potential conflict between flying squirrel conservation and other land uses.

Anticipation and expectation as an affective practice of governance

While professionals make an effort to understand the animal's way of being, they tend to create expectations about its presence. Nygren and Jokinen (2013: 83) have described the bodily capacities, the 'sense of the forest, the eye for the faeces' that flying squirrel surveyors need to develop in order to find the minuscule faecal pellets in the large forest areas they are surveying. They learn to scan the forest for the kind of trees (mainly larger aspen and spruce trees) under which they would most probably find the faeces, which are seen as the most reliable clue of the animal presence (and hence, also conservation obligations). They also look up to see potential nesting places and resting sites, such as nesting holes, nest boxes and dreys. One surveyor also described how despite planning a survey route beforehand, they let the forest guide their survey work. The 'sense of the forest' can be described as habits and routines formed by experience. They guide the gaze and attention in space towards certain features and so the expectation of the presence of the animal grows. The findings the surveyors expect to spot strengthen their view of a potential habitat and of their own surveying skills.

Similar to flying squirrel surveyors, forestry professionals also follow tree species as signs of a habitat suitable for flying squirrel. Forestry professionals have much less experience with observing flying squirrels than the surveyors. Rather than an urge to know and find the animals in order to protect them, their actions are motivated by a sense of obligation. Despite the differences between the two professional practices, the same clues - large aspen and spruce trees - guide the attention of forestry professionals. These clues have been relatively easy for forestry professionals to understand and acquire as they are trained to identify tree species and to monitor forest structure. Tree species and the structure of the forest have thus become an epistemic standard that implies the presence of the animals and prepares both the surveyors and forestry professionals to make observations on flying squirrels. They create an expectation of the presence of the animal and help humans to learn the habits of the animal. 
In relational terms, the flying squirrel's capability to surprise humans emerges from these expectations. The standards that are meant to 'tame' uncertainty related to the animal's presence actually contribute to it, making flying squirrels appear 'feral'.

\section{Conditions for surprises}

The professional practice seems to form conditions for surprising presence/absence of flying squirrels. To understand the wider context of these practices, we need to look at the conservation and surveying practices from which the expectations about the animal behavior and the subsequent surprises emerge.

The way that flying squirrel conservation has been put to practice in Finland places a lot of weight on the findings of caseby-case field surveys, and single findings have the potential to stop, slow down or even move large-scale development projects. Flying squirrel conservation is essentially done placeby-place and wider surveys extending outside each project area that could grasp the metapopulation dynamics of the species are rare. The survey work is usually done in specific sites with land use pressure arising either from land use planning or forest management and usually only once in each place. Ascertaining the presence (or absence) of flying squirrels is very hard and case-by-case surveys can offer only a glimpse to their 'flickering' presence (Hinchliffe 2008; Nygren and Jokinen 2013), leaving much room for unexpected encounters.

Strengthening the mismatch between the conservation objectives and the ecology of the species, and thus the potential impact of the surprises, the current practice of collecting data about flying squirrels is not only patchy, but also leads to essentially too small protected areas (Jokinen 2012). The smaller the conservation area, the more accurate its location should be, which leaves much less space for uncertainty. Siberian flying squirrel individuals use several nests and move in their home range, which ranges from 4 ha (females) to 60 ha (males) (Hanski et al. 2000). The young may disperse as far as $9 \mathrm{~km}$ (Selonen and Hanski 2004) and the average age of flying squirrels is only one year. While the survey practices rely heavily on finding signs of the presence of the animal at the time of the survey, instead of judgement of the suitability (or future suitability) of the habitat in question and the surrounding forest landscape (Nygren and Jokinen 2013), conservation operates on flickering presences. Take an example: a suitable 80 ha forest area that has e.g. 6-8 potential flying squirrel habitat patches of which only a part is occupied by females each year, while males move between the female home ranges. It would be significantly easier to ensure that flying squirrels live in some of these patches during the next 10 years if the whole forest area was managed accordingly than trying to define exactly the borders of the single patches on the basis of observations made during one year.

The practice of conserving small, isolated patches is not ecologically sustainable nor feasible for land use planning, especially in situations where planning processes take years, during which time the forest networks change and the animals may change their habitats, causing surprises during the planning and development processes (Haila et al. 2007). Hence, what matters is the relationship of the nonhuman animals' temporal and spatial scales to human scales of planning and forest management. In fact, similar planning problems arising from the unexpected or flickering presence of nonhuman animals obstructing development projects have arisen with several other species protected by the Habitat Directive in Europe. Mostly they concern animals of similar body and habitat size to flying squirrels, such as moor frogs (Rana arvalis) (e.g Pagh 2005) and hamsters (Cricetus cricetus) (Hajer 2003; Beunen 2006; Eppink and Wätsold 2009), rather than smaller animals such as insects or bigger animals, such as wolves or bears (ECJ 2011).

\section{CONCLUSIONS: IMPLICATIONS OF THE UNEXPECTED FOR NATURE CONSERVATION}

Surprises affect the practices of nature conservation, land use planning and forest management, but they are also essentially co-created by these practices. Surprises often translate to uncertainties which are difficult to address in planning and management. In this sense the formulations of the goal of the Habitat Directive, favorable conservation status and the means to achieve it, e.g. the protection of breeding sites and resting places, give room for species and site- specific adjustment (Kallio 2001; Mehtälä and Vuorisalo 2007). In the case of flying squirrels, the rigid conservation guidelines and practices have, however, given little room for this. Based on our analysis of flying squirrel conservation practices in Finland we conclude that surprises as a politico-corporeal conditions for governance offer a lens through which we can develop more robust conservation practices.

The surprises in policy implementation mean that the practitioners are doing a thorough job. If the surveyors must do their job in a hurry, they will choose to check only the safest, most normal places and do not have time to open up for any surprising findings. For flying squirrel surveyors, surprises can even be a strategic resource in their attuning to the animal ways of living: they may look for possibilities for such attuning by looking for flying squirrels in unlikely places on purpose.

Surprises mean that the object of the policy is influencing policy implementation (Nygren and Jokinen 2013). This implies that nature conservation and policy implementation should be seen as a more-than-human activity. Surveyors and forestry professionals learn to be better surveyors only with the flying squirrels and the forests. They need to be able to learn from the flying squirrels and their choices. Paying attention to surprises is a 'mode of attentiveness' ( $\mathrm{O}$ 'Mahony et al. 2018) that enables us to learn to take the nonhuman others more seriously (Van Dooren et al. 2016), to "decentre as well as rethink the human" (Singh 2018: 3) and to live with and respond to each other better (Haraway 2008; Peltola and Heikkilä 2015, 2018). This resonates with the suggestion of Jamie Lorimer (2015) to consider conservation as a process of 'learning to be affected' by the nonhuman subjects, or as 
Singh (2018: 3) formulates it, to develop affective ecologies and ecopolitics rooted in care. Instead of control, governance and conservation of wild animals must be able to transform with and learn from them and envision new, more responsive ways of conceiving and practicing conservation.

A mindful openness to surprises can help turn what appear as unexpected events into learning processes. Surprises prove that facts are not stable. This is normally considered a problem in conservation that operates in a strictly regulated context: forestry operators and land use planners need to ensure that the known habitats of flying squirrels are secured. Therefore, they need stable facts and guidelines to base their decisions on. Surprises disturb this presupposition. Yet, through our analysis we suggest another possibility to interpret surprises. If acknowledged as 'windows to ignorance' (Gross 2010) or as 'uncomfortable knowledge' that challenges prevailing practices and approaches (Ramírez and Ravetz 2011), they can help identify new knowledge about the animals. Feelings related to surprise, such as becoming perplexed or anxious can encourage to build such knowledge and reconsider situations.

Like any closures that are produced, facts about flying squirrel could be thought of as 'provisional, working categories, that enable rather than disable further learning' (Hinchliffe 2008: 96). Acknowledging that the facts, guidelines or categories needed in making the flying squirrels conservable might be provisional and 'unfinished' urges us to question our assumptions about what is known. But even more importantly, it should lead to refining the ways in which knowledge about the animals and their habitat choices is used in conservation. Flying squirrels should be seen as having adaptive agency in choosing where they decide to live, and instead of merely cataloguing and conserving existing places, conservation should aim at creating more suitable habitats for flying squirrels, and other forest species suffering from the biodiversity crisis. Mindful and responsive management of forests would thus become a tool of conservation.

Our paper has contributed to this goal by documenting the roots of such sentiments that enable the building of more sensitive approaches to conservation, more capable of taking into account the unpredictability of nature.

\section{REFERENCES}

Adey, P. 2008. Airports, mobility and the calculative architecture of affective control. Geoforum 39(1): 438-451.

Anderson, B. 2006. Becoming and being hopeful: towards a theory of affect. Environment \& Planning D: Society \& Space 24(5): 733-752.

Bennett, J. 2010. Vibrant matter. Durham: Duke University Press.

Betz, M. 2020. Pruning the community orchard: methods for navigating human-fruit tree relations. Geographical Review 110(1-2): 224-237.

Beunen, R. 2006. European nature conservation legislation and spatial planning: for better or for worse? Journal of Environmental Planning \& Management 49(4): 605-619.

Boonman-Berson, S., C. Driessen, and E. Turnhout. 2019. Managing wild minds: from control by numbers to a multinatural approach in wild boar management in the Veluwe, The Netherlands. Transactions of the Institute of British Geographers 44(1): 2-15.
Brown, K. and R. Dilley. 2012. Ways of knowing for 'response-ability'in more-than-human encounters: the role of anticipatory knowledges in outdoor access with dogs. Area 44(1): 37-45.

Brunet, L., I. Arpin, and T. Peltola. 2019. Governing research through affects: the case of ecosystem services science. Science \& Public Policy 46(6): 866-875.

Commission v France, case C-383/09, 2011. www.curia.europa.eu. Accessed on August 14, 2020.

Davies, G. 2013. Mobilizing experimental life: spaces of becoming with mutant mice. Theory, Culture \& Society 30(7-8): 129-153.

Duff, C. 2011. Networks, resources and agencies: on the character and production of enabling places. Health \& Place 17(1): 149-156.

Eppink, F.V. and F. Wätzold. 2009. Shedding light on the hidden costs of the habitats directive: the case of hamster conservation in Germany. Biodiversity and Conservation 18(4): 795-810.

Ginn, F. 2014. Jakob von Uexküll beyond bubbles: on umwelt and biophilosophy, Science as Culture 23(1): 129-134.

Gross, M. 2010. Ignorance and surprise: science, society, and ecological design. London: MIT Press.

Haila, Y., M. Kousis, A. Jokinen, N. Nygren, and K. Psarikidou. 2007. Building trust through public participation: learning from conflicts over the implementation of the Gross Habitats Directive. PAGANINI work package 4 , final report.

Hajer, M.A. 2003. Policy without polity? policy analysis and the institutional void. Policy Sciences 36(2): 175-195.

Hanski, I.K. 2006. Liito-oravan pteromys volans Suomen kannan koon arviointi. (Loppuraportti). Helsinki.

Hanski, I.K., P. Stevens, P, Ihalempiä, and V. Selonen. 2000. Home-range size, movements, and nest-site use in the Siberian flying squirrel, Pteromys volans. Journal of Mammalogy 81(3): 798-809.

Haraway, D.J. 2008. When species meet. Minneapolis: University of Minnesota Press.

Hawkins, G. 2010. Plastic materialities. In: Political matter: technoscience, democracy, and public life (eds. Braun, B., S.J. Whatmore, and I. Stengers) Pp. 119-138. Minneapolis: University of Minnesota Press.

Hayes-Conroy, A. 2010. Feeling slow food: visceral fieldwork and emphathetic research relations in the alternative food movement. Geoforum 41(5): 734-742.

Hinchliffe, S. 2008. Reconstituting nature conservation: towards a careful political ecology. Geoforum 39(1): 88-97.

Hyvärinen, E., A. Juslén, , E. Kemppainen, A. Uddström, and U. Liukko. 2019. The 2019 red list of finnish species [suomen lajien uhanalaisuus - punainen kirja 2019]. (). Helsinki: The ministry of the Environment \& Finnish environment Centre. http://hdl.handle.net/10138/299501. Accessed on July 29, 2020.

Ingold, T. 2010. Footprints through the weather world: walking, breathing, knowing. Journal of the Royal Anthropological Institute 16(1): 121-139.

Jokinen, M. 2012. Liito-oravan lisääntymis-ja levähdyspaikkarajausten vaikuttavuus lajin suojelukeinona. Suomen ympäristö 33. Helsinki: Edita.

Jokinen, M., S. Mäkeläinen, and O. Ovaskainen. 2015. 'Strict', yet ineffective: legal protection of breeding sites and resting places fails with the Siberian flying squirrel. Animal Conservation 18(2): 167-175.

Jones, P. 2012. Sensory indiscipline and affect: a study of commuter cycling. Social \& Cultural Geography 13(6): 645-658.

Kallio, P. 2001. Suotuisa suojelutaso luonnonsuojeluoikeudessa. Helsinki: Edita.

Latour, B. 2004. How to talk about the body? the normative dimension of science studies. Body \& Society 10(2-3): 205-229.

Lindenmayer, D.B., G.E. Likens, C.J. Krebs, and R.J. Hobbs. 2010. Improved probability of detection of ecological "surprises". Proceedings of the National Academy of Sciences of the United States of America 107(51): 21957-21962. 
Liukko, U., H. Henttonen, I.K. Hanski, K. Kauhala, I. Kojola, E. Kyheröinen, and J. Pitkänen.2016. The 2015 red list of Finnish mammal species [Suomen nisäkkäiden uhanalaisuus 2015]. (). Helsinki: Ministry of the Environment.

Lorimer, J. 2008. Counting corncrakes: the affective science of the UK corncrake census. Social Studies of Science 38(3): 377-405.

Lorimer, J. 2015. Wildlife in the Anthropocene. conservation after nature. Minneapolis: University of Minnesota Press.

Maguire, R., P. Maguire, and M.T. Keane. 2011. Making sense of surprise: an investigation of the factors influencing surprise judgments. Journal of Experimental Psychology: Learning, Memory, and Cognition 37(1): $176-186$.

Mason, V. and P.R. Hope. 2014. Echoes in the dark: technological encounters with bats. Journal of Rural Studies 33107-33118.

Massumi, B. 2002. Parables for the virtual: movement, affect, sensation. Durham: Duke University Press.

Mehtälä, J.and T. Vuorisalo. 2007. Conservation policy and the EU habitats directive: favourable conservation status as a measure of conservation success. European Environment 17(6): 363-375.

Mäkeläinen, S. 2016. Occurrence, habitat use and movements of the flying squirrel in human-modified forest landscapes. Ph.D. thesis. University of Helsinki, Helsinki, Finland.

Mäkeläinen, S., M. Schrader, and I.K. Hanski. 2015. Factors explaining the occurrence of the Siberian flying squirrel in urban forest landscape. Urban Ecosystems 18(1): 223-238.

Nagel, T. 1974. What is it like to be a bat? The Philosophical Review 83(4): 435-450.

Newman, J. 2012. Beyond the deliberative subject? problems of theory, method and critique in the turn to emotion and affect. Critical Policy Studies 6(4): 465-479.

Nygren, N.V. and A. Jokinen. 2013. Significance of affect and ethics in applying conservation standards: the practices of flying squirrel surveyors. Geoforum 46(1): 79-90.

O’Mahony, K., A. Corradini, and A. Gazzola. 2018. Lupine becomingstracking and assembling Romanian wolves through multi-sensory fieldwork. Society \& Animals 26(2): 107-129.

Pagh, P. 2005. Bestemmer ejeren eller den spidsnudede frø? Ugeskrift for Retsvcesen (3): 25-33.

Peltola, T. and J. Heikkilä. 2015. Response-ability in wolf-dog conflicts. European Journal of Wildife Research 61(5): 711-721.

Peltola, T. and J. Heikkilä. 2018. Outlaws or protected? DNA, hybrids, and biopolitics in a Finnish wolf-poaching case. Society \& Animals 26(2): $197-216$.
Peltola, T. and J. Tuomisaari. 2015. Making a difference: forest biodiversity, affective capacities, and the micro-politics of expert fieldwork. Geoforum 64(1): $1-11$.

Protevi, J. 2009. Political affect: connecting the social and the somatic. Minneapolis: University of Minnesota Press.

Ramírez, R. and J. Ravetz. 2011. Feral futures: Zen and aesthetics. Futures 43(4): 478-487.

Rheinberger, H. and J.S. Fruton. 1997. Toward a history of epistemic things: synthesizing proteins in the test tube. Stanford, CA: Stanford University Press.

Roth, W. and G.M. Bowen. 2001. Of disciplined minds and disciplined bodies: on becoming an ecologist. Qualitative Sociology 24(4): 459-481.

Santangeli, A., I.K. Hanski, and H. Mäkelä. 2013. Integrating multi-source forest inventory and animal survey data to assess nationwide distribution and habitat correlates of the Siberian flying squirrel. Biological Conservation 157(0): 31-38.

Santangeli, A., R. Wistbacka, I.K. Hanski, and T. Laaksonen. 2013. Ineffective enforced legislation for nature conservation: a case study with Siberian flying squirrel and forestry in a boreal landscape. Biological Conservation 157(0): 237-244.

Selonen, V. and I.K. Hanski. 2004. Young flying squirrels (pteromys volans) dispersing in fragmented forests. Behavioral Ecology 15(4): 564-571.

Selonen, V., P. Sulkava, R. Sulkava, S. Sulkava, and E. Korpimäki. 2010. Decline of flying and red squirrels in boreal forests revealed by long-term diet analyses of avian predators. Animal Conservation 13(6): 579-585.

Singh, N.M. 2018. Introduction: affective ecologies and conservation. Conservation and Society 16(1): 1-7.

Thomson, M.S. 2007. Placing the wild in the city:" thinking with" Melbourne's bats. Society \& Animals 15(1): 79-95.

Van Dooren, T., E. Kirksey, and U. Münster. 2016. Multispecies studies. cultivating arts of attentiveness. Environmental Humanities 8(1): 1-23.

Vanhanen, J. 2010. Encounters with the virtual: the experience of art in gilles deleuze's philosophy. Ph.D. thesis. University of Helsinki, Helsinki, Finland.

Wistbacka, R., M. Orell, and A. Santangeli. 2018. The tragedy of the sciencepolicy gap-revised legislation fails to protect an endangered species in a managed boreal landscape. Forest Ecology and Management 422172-422178.

Von Uexküll, J. 2013. A foray into the worlds of animals and humans: with a theory of meaning . Minneapolis: University of Minnesota Press.

Vuorisalo, T., H. Andersson, T. Hugg, R. Lahtinen, H. Laaksonen, and E. Lehikoinen. 2003. Urban development from an avian perspective: causes of hooded crow (corvus corone cornix) urbanisation in two Finnish cities. Landscape and Urban Planning 62(2): 69-87. 